\title{
CONSIDERAÇÕES SOBRE A JUSTIFICAÇÃO DE KANT ACERCA DA PROPRIEDADE PRIVADA
}

\author{
Notes on Kant's justification \\ of private property \\ Consideraciones acerca de la justificación de Kant \\ sobre la propiedad privada
}

Joel Thiago Klein'

Universidade Federal de Santa Catarina, Florianópolis, SC, Brasil.

\section{Resumo}

Neste artigo fazem-se algumas considerações sobre a justificação da propriedade privada na filosofia do direito de Kant. A partir da análise do conceito de lei permissiva da razão, defende-se que na filosofia do direito opera uma perspectiva teleológico-reflexionante de caráter prático, a qual permite compreender, por um lado, que a propriedade no estado de natureza seja legítima ao mesmo tempo em que é problemática, enquanto, por outro lado, o estado civil envolve a exigência de que a propriedade seja adequada segundo as condições de um sistema de justiça distributiva.

Palavras-chave: Kant. Propriedade. Lei permissiva. Direito. Teleologia.

\footnotetext{
Doutor em Filosofia pela Universidade Federal de Santa Catarina (UFSC), Florianópolis, SC, Brasil. Professor do Departamento de Filosofia da Universidade Federal de Santa Catarina (UFSC), Florianópolis, SC, Brasil. Bolsista produtividade em Pesquisa do CNPq. https://orcid. org/0000-0003-2665-9113. E-mail: jthklein@yahoo.com.br
} 


\begin{abstract}
This paper presents some notes on the justification of private property in Kant's philosophy of law. From the analysis of the concept of permissive law of reason, it is argued that in Kant's philosophy of law operates a teleological-reflective perspective of a practical nature, which allows to understand, on the one hand, that property in the state of nature is legitimate and still problematic and, on the other hand, that property in the civil state is placed under the requirement of a system of distributive justice.
\end{abstract}

Keywords: Kant. Property. Permissive law. Law. Teleology.

\title{
Resumen
}

Este artículo hace algunas consideraciones para la justificación de la propiedad privada en la filosofía del derecho de Kant. Desde el análisis del concepto de ley permisiva de la razón, se argumenta que en la filosofía del derecho opera en una perspectiva teleológica-reflexionante de carácter práctico, que permite entender, por un lado, que la propiedad en el estado de naturaleza sea legítima mientras que sea problemática pero que, por otro lado, el estado civil implica el requisito de que la propiedad sea apropiada según las condiciones de un sistema de justicia distributiva.

Palabras clave: Kant. Propiedad. La ley permisiva. Ley. Teleología.

\section{Introdução}

A justificação da propriedade privada em Kant depende do conceito bastante problemático e disputado de lei permissiva da razão. Por isso, grande parte desse artigo se dedica a uma análise detalhada desse conceito, para em seguida retirar algumas consequências para a compreensão do conceito de propriedade. Divido esse artigo em três seções. A primeira apresenta o estado da arte das interpretações acerca do conceito de lei permissiva, indicando também os seus problemas. Na segunda seção, apresento a minha interpretação da lei permissiva como um desdobramento teleológico do princípio da moral e do direito, indicando as vantagens com relação às demais interpretações existentes. Por fim, na terceira seção, indico as consequências de minha leitura para a questão da justificação 
da propriedade privada em Kant, tanto a partir da perspectiva do direito civil, quanto do direito cosmopolita ${ }^{2}$.

\section{0 estado da arte acerca da lei permissiva}

Apesar de haver variantes, é possível mapear basicamente três grandes vertentes de interpretação da lei permissiva. No que segue apresento os aspectos gerais dessas interpretações e seus respectivos problemas. Seguindo uma certa ordem cronológica, a primeira é a perspectiva inaugurada por Brandt e nomeada por Flikschuh como "obscuro julgamento preliminar". A segunda é apresentada por Tierney e pode ser considerada como resultado de uma ambiguidade sistêmico-conceitual. A terceira é defendida por Hruschka e considera a lei permissiva como uma "norma que confere poder".

\subsection{Lei permissiva como "exceção a uma proibição" ou "obscuro julgamento preliminar"}

Brandt (em seu artigo de 1982 que foi republicado em 2004) defende que as leis permissivas da razão não se referem à autorização de realizar ações que são moralmente neutras, isto é, ações que estariam no campo das ações indiferentes (adiaphora). Nesse caso, como as ações obrigatórias já envolveriam uma autorização, segue-se que se fala de leis permissivas apenas quando se trata de autorizar ações que em um determinado sentido são proibidas 3 . Utilizando-se da consideração feita por Kant no ensaio À paz perpétua $(Z e F)^{4}$, de que a razão sistematicamente classificadora

\footnotetext{
2 O presente trabalho foi realizado com apoio da Coordenação de Aperfeiçoamento de Pessoal de Nível Superior- Brasil (CAPES) - Código de Financiamento 001. Esse trabalho também recebeu apoio da Alexander von Humboldt Stiftung.

3 Cf. BRANDT, 2004, p. 71.

4 Todas as citações das obras de Kant seguem as regras da Akademie Ausgabe. Utiliza-se as seguintes siglas: ZeF: À paz perpétua; MS: Metafísica dos Costumes; KrV: Crítica da razão pura; TP: Sobre a expressão corrente isso pode ser correto na teoria, mas não serve para a prática; SF: Conflito das faculdades.
} 
apresenta por si só o conceito de uma lei permissiva, Brandt estabelece um paralelo entre a modalidade dos juízos práticos com a modalidade dos juízos teóricos. Nesse sentido, os mandamentos (leis que comandam a realização de uma ação) estariam para os juízos afirmativos, as proibições (leis que proíbem a realização de uma ação) para os juízos negativos, enquanto as leis permissivas estariam para os juízos infinitos ${ }^{5}$. De forma semelhante, da perspectiva da modalidade, as leis permissivas deveriam ser postas na perspectiva dos juízos práticos problemáticos, isto é, de juízos aos quais não se possui fundamento o suficiente para sustentar sua certeza, o que por sua vez, é exatamente o que distingue o direito provisório, no estado social, do direito peremptório no estado civil. ${ }^{6}$

Nas palavras de Brandt: "o lugar sistemático das leis permissivas jurídicas ocorre claramente na mediação entre mandamentos e proibições: trata-se de permitir provisoriamente algo que é 'em si' proibido e assim obrigar que não tenha efeito a pretensão de direito de se contrapor a essa transgressão"7. Nesse sentido, Kant estaria falando em ZeF (AA 8:348) de uma permissão para se continuar com a posse de algo que foi adquirido ilegitimamente. Em outras palavras, a lei permissiva funda um modo jurídico de conivência com formas de poder inevitáveis, que já ocorreram e estão concretizadas institucionalmente ${ }^{8}$. Segundo Brandt, a função dessa conivência provisória com uma proibição é funcionar, ao modo semelhante da teleologia da natureza e da cultura, como uma ponte entre o abismo da simples natureza e a moralidade completa 9 . Essa função de mediação, entre o prescritivo e o descritivo, entre aquilo que estabelece a lei moral e a realidade fenomênica, é exatamente o que envolve a questão da aplicação de uma concepção reformista de Kant no

\footnotetext{
Cf. BRANDT, 2004, p. 73.

Cf. BRANDT, 2004, p. 76.

Cf. BRANDT, 2004, p. 74.

8 Cf. BRANDT, 2004, p. 76.

9 Cf. BRANDT, 2004, p. 79.
} 
contexto político, a saber, com relação à revolução francesa e aos projetos de reforma dinásticas na Prússia e Áustria ${ }^{10}$.

Flikschuh"1 leva adiante essa interpretação e com base nas considerações de Brandt sobre a peculiaridade dos juízos problemáticos nomeia a lei permissiva como um "obscuro julgamento preliminar". De forma semelhante a Brandt, ela também afirma que as leis permissivas existem somente no âmbito da política e não da ética (pois na ética ações indiferentes não seriam objeto de leis, já que isso levaria a uma micrologia) ${ }^{12}$. $\mathrm{Na}$ política as leis permissivas "se aplicam a ações que, com base em circunstâncias políticas que não permitem outra possibilidade, devem ser consideradas como provisoriamente legais, ainda que de um ponto de vista estrito sejam ilegais. Leis permissivas valem como provisoriamente justas, elas são validas em antecipação e em preparação para a institucionalização das leis que estão de acordo com os requerimentos da razão prática pura"13. Com base nessa leitura, Flikschuh reinterpreta a antinomia da propriedade no direito privado no sentido de que se trata de uma autorização que precisa ser gradualmente corrigida, tarefa tanto do direito civil, quando do direito cosmopolita.

10 Cf. BRANDT, 2004, p. 83. Essa leitura iniciada por Brandt e levada adiante por Flikschuh (2000) encontra aceitação em diversos outros intérpretes, que aplicam essa mesma tese para repensar outros momentos da filosofia política kantiana. Entre eles estão, por exemplo, Ypi (2012), Kleingeld, (2012), Loriaux (2017).

1 Cf. FLIKSCHUH, 2000.

12 Aqui apenas mencionarei an passant uma crítica a essa tese de que as leis permissivas se restringem a um contexto jurídico e não possuem uma contrapartida no campo da ética. 0 argumento de Brandt (2004, p. 70), o qual Flikschuh simplesmente segue, assenta-se na leitura de uma passagem da Doutrina da virtude, a saber, 06:409. Entretanto essa passagem não está afirmando que não podem existir lex permissivae no âmbito da ética, Kant está somente mencionando que não se deve cair no erro de regular questões que são indiferentes para a razão prática, pois isso levaria a uma micrologia. Ora, a mesma coisa também poderia ser dita para o âmbito do direito. A questão das leis permissivas se refere a ações que não são ordenadas nem proibidas, mas que também não são indiferentes para a razão. Esse é todo o ponto. Se fossem indiferentes a razão não precisaria de leis para as regular. Se o direito quisesse estabelecer leis permissivas para tudo que é indiferente para a razão prática também cairia em uma micrologia. Em suma, talvez não existam leis permissivas no âmbito da ética, mas o argumento que Brandt menciona não basta para estabelecer isso.

13 FLIKSCHUH, 2000, p. 138. 
Jacob Weinrib apresenta três críticas a essa leitura iniciada por Brandt, a qual ele sintetiza como "uma autorização para se realizar uma exceção a uma proibição geral tendo em vista a realização de um fim obrigatório." ${ }^{14} A$ primeira crítica se refere ao fato de Kant em ZeF constantemente acentuar a ideia de que "a lei permissiva não autoriza a autoridade pública a realizar exceções na regra do direito"15. Como aponta Weinrib, a permissão que Kant fala em ZeF não se refere à exceção a uma proibição, mas a uma autorização para se postergar uma reforma, ou seja, a proibição se refere a um ato futuro, enquanto a exceção se refere a um ato presente ${ }^{16}$. A segunda crítica se refere ao fato de que na Metafísica dos Costumes Kant não fala acerca da realização de um fim obrigatório, ao contrário, Kant estaria vinculando as leis permissivas a ações que são moralmente indiferentes ${ }^{17}$. A terceira crítica se refere a um problema sistemático estrutural que a leitura de Brandt enfrentaria no âmbito da Doutrina do Direito, a saber, que a perspectiva de uma exceção a uma proibição entraria em conflito com o imperativo "não faças mal a ninguém (neminem laede), ainda que tenhas de abandonar com isso toda ligação com os outros e evitar qualquer sociedade (Lex juridica)"18. Ora, "enquanto que Brandt fala de em uma autorização para se cometer um dano para que se possa entrar em uma condição na qual se possa associar com outros juridicamente, Kant explicitamente defende a posição de que se deve evitar cometer danos, mesmo se isso significasse que não se poderia associar com outros"19.

Essas críticas de Weinrib são pertinentes (ao menos a primeira e a terceira, visto que a segunda será refutada no que se segue), mas a sua própria interpretação, que pretende explicar a diferença entre as

\footnotetext{
14 WEINRIB, 2013, p. 110.

15 WEINRIB, 2013, p. 110.

16 WEINRIB, 2013, p. 122.

17 WEINRIB, 2013, p. 111.

18 MS 6:236.

19 WEINRIB, 2013, p. 111.
} 
passagens da ZeF e da MS com base na distinção entre os contextos do direito privado e do direito público, também é insuficiente para esclarecer o conceito de lei permissiva, especificamente por que não consegue dar unidade ao próprio conceito de lei permissiva na obras de Kant. Claro que pode haver diferenças entre o âmbito do direito privado e do direito público, mas para que um mesmo conceito seja utilizado em ambos os domínios, deve haver um núcleo comum, e é exatamente esse núcleo comum que Weinrib não consegue estabelecer. Ele mostra apenas que não se trata de uma exceção a uma proibição, mas falar o que algo não é, não significa estabelecer uma positividade no conteúdo conceitual da lei permissiva. Nesse sentido, quando se trata de levar adiante uma interpretação positiva do significado da lei permissiva, ele simplesmente segue a leitura de Hrushka. Em outras palavras, Weinrib não fala que o conceito de lei permissiva em ZeF e em MS estão em oposição, como Hruschka o faz (ver 2.3), mas ele também não consegue mostrar o que liga ambos os conceitos. Em suma, se há pertinência nas suas críticas à leitura de Brandt, a sua própria posição também não captura o verdadeiro problema da leitura de Brandt, mas apenas os seus problemáticos efeitos.

Acredito que o real problema da leitura de Brandt foi não atentar suficientemente para a própria estrutura lógico-transcendental presente no conceito de juízo infinito e na sua relação com a lei permissiva. Ora, se se vincula a lei permissiva ao aspecto da qualidade envolvida no juízo infinito, então não se pensa a lei permissiva como uma exceção a uma proibição, mas sim como exceção a uma ordem. Note-se que na Crítica da razão pura Kant afirma que na perspectiva da lógica geral não haveria problema em reduzir os juízos infinitos à categoria dos juízos afirmativos, ainda que isso não poderia ser feito no caso da lógica transcendental, a qual não abstrai completamente da consideração do conteúdo. Ora, de uma perspectiva da lógica geral, os juízos infinitos deveriam ser vinculados aos juízos afirmativos e não aos juízos negativos.

Mutatis mutandis, no âmbito prático isso teria como equivalente o fato de que as leis permissivas deveriam ser vinculadas antes aos mandamentos 
do que às proibições. Brandt recusa considerar essa possibilidade, pois ele pressupõe que no dever de realizar uma ação, já está implícita uma permissão, ou seja, vincular a lei permissiva a um mandamento seria uma tautologia. A questão, entretanto, é que quando se fala que o mandamento de uma ação implica já uma permissão, está se afirmando algo distinto de quando se afirma que se está abdicando de um mandamento. Em outras palavras, o mandamento ou a lei preceptiva define de maneira positiva e prática a realização de uma ação, enquanto na lei permissiva abdica-se de assumir o que é estabelecido pela lei preceptiva, ainda que acabe aceitando a realização de um determinado ato que seria o mesmo, caso fosse estabelecido pela lei preceptiva. Da perspectiva da lógica geral isso pode ser o mesmo, mas quando se está tratando com os desdobramentos da lógica transcendental e, por conseguinte, com um certo conteúdo dado a priori, essa pequena diferença possui importantes consequências.

Isso significa que a leitura de Brandt implica o seguinte modelo: a) mandamentos ou lei preceptiva: "Trata-se de fazer X"; b) proibições ou lei proibitiva: "Trata-se de proibir X" ou "trata-se de não fazer X"; c) lei permissiva: "trata-se de fazer o proibido $X$ " ou "não se trata de não fazer $X$ ". Isso significa que a lei permissiva implica relevar em um certo momento o não cumprimento de não se fazer $X$, ou ainda, uma exceção à proibição $X$. Isso teria como consequência para a filosofia do direito como um todo a questão de que se estaria permitindo adentrar no sistema algo que é fundamentalmente equivocado, imoral. No caso do direito privado e da propriedade, por exemplo, isso significaria que todo o direito provisório, que trata da posse jurídica no estado de natureza, estaria fundado numa conivência acerca de uma proibição. Em outras palavras, o direito surgiria em seu primeiro momento como sendo algo essencialmente corrompido, ou ainda, implicaria uma cumplicidade com uma infração.

A leitura que estou propondo tem o seguinte modelo: a) mandamento ou lei preceptiva: “Trata-se de fazer X"; b) proibições ou lei proibitiva: "Trata-se de proibir X" ou "trata-se de não fazer X"; c) lei permissiva: "trata-se de fazer não X", ou ainda "trata-se de fazer o não proibido X". 
Nesse sentido, uma lei permissiva está afirmando que algo não é objeto de mandamento, mas isso também não significa que esse algo deva ser considerado uma proibição. Para a justificação do direito isso implica que seu fundamento não inicia a partir de um princípio que já comporta logicamente um momento negativo ou ainda, uma corrupção, mas apenas de um princípio que enuncia a possibilidade de se fazer algo que a razão não ordenou e que não é proibido. Em outras palavras, trata-se, na verdade, de um aspecto positivo de exercício da liberdade, isto é, da liberdade de se realizar um ato que não é mandatório. Ou ainda, a lei permissiva indica antes de tudo uma positividade.

Assim, por exemplo, em À paz perpétua não se trata de descumprir um dever, ainda que de um modo apenas temporário, mas sim do direito do soberano de postergar uma reforma para um momento conveniente. Existe a obrigação da reforma, mas não a realização da reforma de maneira súbita e completa, pois tal obrigação impediria a própria realização do fim do direito. Também na Doutrina do direito não se trata de descumprir uma proibição, a proibição de não tomar algo sem dono como seu, mas sim do direito que cada um tem, enquanto membro da espécie humana e coproprietário original da terra, de tomar algo como exclusivamente seu, ou ainda, de realizar algo que não é proibido. Existe uma obrigação de se fazer essa especificação exclusiva segundo a ideia do direito como sistema, mas não que essa condição tenha de ser implementada desde o início, desde a primeira posse, até porque tal obrigação impediria a própria realização do fim do direito, uma vez que esse critério seria impossível de ser implementado desde o início, ou seja, como sendo representável na ideia de história como factível.

A partir dos dois excertos sobre a lei permissiva em À paz perpétua, isso não fica completamente claro, pois também há uma menção direta a uma proibição. Na verdade, esse é um problema que está na base do próprio conceito de juízo infinito. O juízo negativo estabelece uma negação na cópula (a alma não é mortal), enquanto o juízo infinito estabelece uma negação no predicado (a alma é não mortal / ou imor- 
tal). Como mencionado anteriormente, na Crítica da razão pura ( $K r V$ ) os juízos infinitos são colocados de uma perspectiva lógica ao lado dos juízos positivos. Já na Jäsche Logik há uma ambiguidade, por um lado, Kant afirma que os juízos infinitos contêm uma restrição, mas essa restrição é sempre ainda "uma ação positiva", porém, por outro lado, da perspectiva da lógica geral os juízos infinitos não seriam distinguidos dos negativos. Entretanto, segundo as lições da Vienna Logik e da Dhona-Wundlacken Logik os juízos infinitos são postos, assim como na $K r V$, ao lado lógico dos juízos afirmativos. Em suma, de uma perspectiva lógica os juízos infinitos são colocados do lado dos juízos afirmativos, mas eles também contêm em si uma negatividade. Em certo sentido, isso também é indicado na $K r V$, segundo a qual o terceiro momento das categorias envolve uma combinação dos outros dois momentos.

Para esclarecer esse ponto e apresentar a complexidade do problema, vale a pena citar um texto da Vienna Logik:

Afirmação e negação são respectivamente qualidades do juízo. Um juízo negativo não é simplesmente qualquer juízo que é negativo, mas um juízo negativo no qual a negação afeta a cópula. Um juízo é afirmativo, por sua vez, quando a negação não afeta a cópula, mas o predicado, como ocorre nos juízos infinitos nos quais a cópula está sem qualquer negação. Consequentemente, todos os juízos infinitos são afirmativos, pois a negação afeta apenas o predicado. Mas embora todo juízo negativo possua a natureza dos juízos afirmativos, todavia, sempre há uma negação presente, não no julgamento, isto é, na relação entre os conceitos, mas no predicado. A relação é, obviamente, a mesma dos juízos afirmativos, mas a negação está ainda sempre presente e, consequentemente, os juízos infinitos são distintos dos juízos afirmativos. Na lógica, essa é uma questão de mera sutileza. Mas na metafísica isso será uma questão importante para a qual se precisa atentar, pois lá a distinção entre realidade, negação e limitação é grande. No caso de limitações, eu 
penso algo positivo, mas não algo meramente positivo, mas algo negativo também, e isso é algo positivo que se encontra restringido. Eles são chamados de judicia infinita porque são ilimitados. Eles apenas dizem aquilo que não é e eu posso fazer incontáveis predicados desse sentido, pois a esfera dos predicados afetados pelo 'não' que se relaciona com o sujeito é infinita ${ }^{20}$.

Se levarmos em conta esse aspecto do juízo infinito, a saber, de que ele traz consigo "algo positivo que é restringido", então se consegue compreender melhor o momento lógico da passagem de uma posse coletiva da terra para a propriedade privada, ou seja, trata-se de uma positividade que é limitada. Claro que a limitação envolve também uma negatividade, mas não uma negatividade que fica em primeiro plano, ou ainda, uma negatividade definida e definitiva, pois uma das características do juízo infinito é exatamente a de que ele não define o que um objeto é, mas apenas o que ele não é. Para a questão da propriedade, isso teria como consequência que o seu estabelecimento não é mais uma posse coletiva originária, mas não que ela não possa ou não deva envolver um conjunto de restrições à propriedade privada, pois, no final das contas, não se disse nada positivo e definitivo com relação a como essa propriedade pode ser exercida. Na verdade, a positividade dessa aquisição de algo como meu será determinada a partir do conceito de um sistema de direitos fundado na ideia de vontade geral e na realização da liberdade, que funcionará sempre como ideal teleológico regulativo.

Ora, estamos diante de uma situação em que um indivíduo diria que um copo está meio cheio, enquanto outro indivíduo diria que o copo está meio vazio. Kant afirmaria que o copo está meio cheio, uma vez que antes o copo estava vazio, mas claro que o aspecto de estar meio cheio é definido também a partir da negatividade daquilo que lhe falta, ou seja, do meio vazio. Entretanto, além disso, e esse é um aspecto bastante

20 V-Log/Wiener, AA 24:929f (grifo nosso, tradução nossa). 
relevante, há a demanda prática de que ele se torne cada vez mais cheio, ainda que talvez nunca completamente cheio, regulativamente falando. Nas palavras de Kant:

São leis permissivas da razão conservar a situação de um direito público, viciado pela injustiça, até por si mesma estar madura para uma transformação plena ou se aproximar da sua maturação por meios pacíficos; pois qualquer constituição jurídica, embora só em grau mínimo seja conforme ao direito, é melhor do que nenhuma, uma reforma precipitada depararia com o seu último destino (a anarquia) ${ }^{21}$.

Isso também pode ser visto na primeira passagem da $Z e F$ que trata da lei permissiva. Em primeiro lugar, indica-se sua positividade:

Pois as leis em geral contêm um fundamento de necessidade prática objetiva, mas a permissão contém um fundamento da contingência prática de certas ações; por isso, uma lei permissiva conteria o constrangimento a uma ação a que não se pode estar obrigado, o que seria uma contradição se o objeto da lei tivesse o mesmo significado em ambos os $\operatorname{casos}^{22}$.

Em outras palavras, a lei permissiva implica certa contingência e por isso não pode ser ordenada, ou ainda, não pode ser formulada como um mandamento ou lei preceptiva. Contudo, a negatividade inerente também é logo em seguida sinalizada:

Mas agora aqui, na lei permissiva, a suposta proibição refere-se apenas ao modo de aquisição futura de um direito (por exemplo, por herança), ao passo que o levantamento da proibição, isto é, a permissão, refere-se à posse presente, a qual pode ainda persistir segundo uma lei permissiva do direito natural na transição do estado de natureza para o estado civil como uma posse, se não conforme ao direito, no

21 ZeF, AA 08: 373, n (grifo nosso).

22 (ZeF, AA 08: 348n (grifo nosso). 
entanto, sincera (possesio putativa). Ora, uma posse putativa, logo que se reconheceu como tal, é proibida no estado de natureza do mesmo modo que um tipo semelhante de aquisição é proibido no posterior estado civil (após a passagem) $[. . .]^{23}$.

A lei permissiva assume que uma determinada posse putativa ocorreu de boa fé e é, portanto, legítima. Mas esse procedimento não deve continuar ocorrendo no futuro, ou seja, essa positividade inicial é limitada aos casos passados, enquanto se lhe proíbe para os casos futuros. Esse aspecto da boa fé também é o pressuposto inicial de todo o sistema de direito na MS, isto é, o princípio "honeste vive" ou "sê um homem honesto"24 que está na base da divisão dos direitos.

\subsection{Lei permissiva como paradoxo}

Tierney propõe lançar luz às dificuldades concernentes à lei permissiva a partir da reconstrução de um contexto histórico mais amplo, uma vez que, segundo ele, "o conceito de lei permissiva foi discutido por juristas e filósofos políticos por vários séculos antes de Kant assumir o argumento"25. Entretanto, essa reconstrução histórica não é determinante para ajudar a esclarecer o sentido da posição de Kant. Assim, Tierney assevera que "se fica com a impressão de que Kant estava tentando fazer com que a ideia da lei permissiva executasse mais tarefas do que lhe poderia caber"26. Esse alegado paradoxo é formulado por ele da seguinte maneira:

Dois modos de argumentar correm paralelos ao longo da obra de Kant. Se, como ele às vezes sugere, o ato da aquisição originária era inerentemente legítimo visto que

\footnotetext{
$23 \mathrm{ZeF}, \mathrm{AA}$ 08: $348 \mathrm{n}$.

24 MS, AA 06:236.

25 TIERNEY, 2001, p. 302.

26 TIERNEY, 2001, p. 312.
} 
ele conduziu ao eventual estabelecimento da sociedade civil e devido ao dever de todos os outros de entrar em tal sociedade, então nenhuma especial lei permissiva teria sido necessária. Se, aquele ato foi em si mesmo ilegítimo na medida em que constrangeu a liberdade dos outros de modo injustificado, mas foi justificado mediante a invocação da lei permissiva, então surge um problema mais profundo. Como o argumento de Kant se desenvolve, parece que a lei natural está em conflito com ela mesma ${ }^{27}$.

Desse ponto de vista, Tierney não segue o caminho que atribui essas dificuldades a uma alegada senilidade de Kant. Entretanto, de acordo com ele "tem-se a impressão de uma poderosa mente buscando, com todo o refinamento da habilidade e sutileza, pela solução de um problema que era insolúvel dentro dos parâmetros que Kant estabeleceu para ele próprio"28.

Essa interpretação de Tierney é basicamente negativa, uma vez que chega a conclusões que sugerem o abandono dos princípios e do contexto sistemático-filosófico nos quais opera a filosofia kantiana. Curiosamente, essa conclusão é alcançada muito mais como o resultado de uma comparação da solução kantiana com a tradição filosófica anterior e sua incapacidade de adaptar um determinado conceito filosófico a uma filosofia com pretensões exclusivamente a priori. A meu ver, falta a essa perspectiva um pouco mais de atenção e compreensão com relação ao próprio sistema filosófico desenhado por Kant e de como ele opera metodologicamente. Em suma, trata-se de uma abordagem que pretende esclarecer um conceito a partir de uma perspectiva mais histórica do que sistemática. Dessa forma, simplesmente desconsidera que tal conceito possa ter sido desenvolvido num contexto sistemático próprio, mesmo que seu autor seja conhecido exatamente por sua preocupação com a

27 TIERNEY, 2001, p. 311.

28 TIERNEY, 2001, p. 399. 
unidade sistemática de seu pensamento. De todo modo, essa leitura tem o mérito de apontar para um ponto importante, que é o reconhecimento de que a lei permissiva precisa tratar com o particular e o contingente, algo que para Tierney conduziria a filosofia kantiana inevitavelmente a paradoxos. A meu ver, o equívoco dessa leitura é não perceber que no sistema de Kant há uma metodologia específica para lidar com esse tipo de questão, a saber, o vínculo entre o a priori e o a posteriori.

\subsection{Lei permissiva como uma "norma que confere poder"}

Hruschka parte do pressuposto de que se deve abandonar a tentativa de construir uma leitura unitária em torno dos usos que Kant faz do conceito de lei permissiva. Segundo ele, na Metafísica dos Costumes Kant rejeitaria as suas posições anteriores, isto é, aquelas apresentadas nas Lições de Metafísica dos Costumes Vigilantius proferidas em 1793-94 e no ensaio À paz perpétua em 1795. Dessa forma, segundo ele, a lei permissiva deve ser interpretada na sua versão final tal como aparece estritamente na Metafísica dos Costumes. ${ }^{29}$

A partir de uma reconstrução histórico e filológica do uso da lei permissiva no contexto filosófico-jurídico da época, especialmente a partir de autores como Achenwall e Thomasius, Hruschka propõe interpretar a lei permissiva como uma "norma que confere poder"30. Nesse caso, as leis permissivas são normas que autorizam seu beneficiário a colocar outros sob uma obrigação simplesmente por realizar uma ação permitida. Nesse sentido, a lei permissiva estabelece que ações meramente permitidas passem a ter significado jurídico.

A análise de Hruschka a partir da passagem 6:223 indica que existem dois tipos de ações permitidas, as ações permitidas que são indiferentes (adiaphoron) e as ações permitidas que possuem implicações jurídicas, as quais são denominadas de "meramente permitidas". Exemplos da

29 Cf. HRUSCHKA, 2004, p. 46.

30 HRUSCHKA, 2004, p. 47. 
primeira seria beber leite, da segunda adquirir objetos externos como seus $^{31}$. Nesse sentido, lê-se:

Kant, entretanto, não é da opinião que todas as ações meramente permitidas requeiram uma lei permissiva. Como Kant enfatiza, nenhuma lei permissiva é necessária para ações moralmente neutras (adiaphora). Ainda assim, mesmo quando tenho liberdade de fazer certas ações tal como me apetece, essas ações podem todavia necessitar estar fundadas em uma regra, a qual Kant nomeia de 'lei permissiva', do contrário, eu não teria liberdade de fazer ou deixar de fazê-las segundo minha vontade. Na 'Introdução à metafísica dos costumes' Kant não responde à questão de se uma tal lei é necessária ou não. Ele deixa isso expressamente em aberto. Na Doutrina do direito, entretanto, ele parte da pressuposição de que a lei permissiva é necessária em alguns $\operatorname{casos}^{32}$.

As consequências teóricas dessa leitura recaem especificamente sobre o caráter que assume a propriedade tanto no contexto do direito privado, como na relação entre estado e propriedade. Segundo ele, a lei permissiva introduz e estabelece instituições jurídicas. Por sua vez, essas instituições jurídicas fornecem fundamentos para direitos a objetos do arbítrio humano, tal como o direito a ter propriedade, o direito de colocar em vigor relações contratuais e o direito a exercer o poder paterno. Esses direitos não dependem da aceitação social, mas se seguem a priori como uma extensão da razão prática pura. Assim o estado é obrigado a reconhecê-los e protegê-los ${ }^{33}$.

${ }_{31}$ Cf. HRUSCHKA, 2004, p. 48.

32 HRUSCHKA, 2004, p. 54.

33 HRUSCHKA, 2004, p. 47. 
Em outras palavras, segundo essa interpretação a lei permissiva possui um estatuto jurídico perfeito, sendo que a função do estado seria simplesmente criar instituições que resguardem o que foi adquirido no estado social. ${ }^{34}$

Entretanto, a meu ver, a leitura de Hruschka padece dos seguintes problemas:

a) É estranho e pouco provável que Kant tenha mudado de opinião entre 1795 e 1797. Em primeiro lugar, não há nenhum indício de que ele o tenha feito. $\mathrm{O}$ argumento de que algo semelhante tenha ocorrido com os conceitos de vontade e arbítrio 35 não é um bom argumento, pois é muito mais razoável defender que Kant não mudou de opinião também quanto a esses conceitos, mas que ele apenas introduz uma especificação que desde sempre estava implícita (como entre desejar e querer na Fundamentação da metafísica dos costumes). Em segundo lugar, não há nenhum indício de que tenha havido uma mudança radical de Kant acerca da teoria de Achenwall, pois isso implicaria pressupor que Kant ou não reconhecia a importância do conceito de Achenwall dois anos antes, ou que ele discordava dele naquele momento. Não há registro de nenhum dos dois casos. Em suma, o fato de uma interpretação não apresentar uma teoria unitária da lei permissiva não é definitivo para desqualificá-la, entretanto com certeza esse

34 Com alguma variação, essa leitura de Hruschka da lei permissiva como uma "norma que confere poder" encontra aceitação e desenvolvimento também em Kaufman (2005), o qual faz uma reconstrução histórica ainda mais antiga do conceito de lei permissiva. Entretanto, diferente de Hruschka, Kaufman assinala que o próprio conceito de lei permissiva não é ainda suficiente para assegurar uma interpretação mais liberal de Kant, pois ainda seria possível encontrar passagens que o aproximariam de Rousseau e de uma visão do Estado como agente atuante num processo de estabelecimento de igualdade. Também Weinrib (2014) segue Hruschka, mas acentua que não seria preciso distinguir a interpretação entre À Paz perpétua e a Metafísica dos costumes, caso se acrescentasse uma distinção entre a esfera e as características do direito privado e a esfera e as características do direito público.

35 Cf. HRUSCHKA, 2004, p. 54. 
indica um ponto desfavorável, especialmente por se tratar de textos temporalmente tão próximos.

b) Trata-se de uma interpretação que acentua muito mais eventuais aspectos históricos do que razões sistemáticas. Não se trata de sustentar que elementos históricos não possuem importância, mas num autor como Kant, que assume uma postura abertamente "antropófoga" com a história da filosofia ${ }^{36}$, e, além disso, que continuamente acentua a importância de uma perspectiva sistemática ${ }^{37}$, com certeza razões de ordem histórica ficam em segundo plano e são hierarquicamente inferiores às razões de ordem argumentativa e sistemática.

c) A análise textual de Hruschka, a qual pretende estabelecer uma nomenclatura diferenciativa entre "ações permitidas" e "ações meramente permitidas" e com isso uma equivalência com a nomenclatura de Achenwall entre "actio licita" e "actio permissa" é artificial e frágil. Ele próprio parece ter de forçar sua leitura sobre o texto de Kant em uma nota de rodapé ao propor uma leitura específica da palavra alemã "allemal"38. Ao meu ver, isso já mostra a artificialidade da sua tentativa de fazer seu ponto. A sentença de Kant: "Se é assim, a autorização nem sempre diz respeito a uma ação indiferente (adiaphoron), pois para uma tal ação, se considera de acordo com leis morais, não seria requerida nenhuma lei particular ["Wenn dieses ist, so würde die Befugniß nicht allemal eine gleichgültige Handlung ( adiaphoron) betreffen; denn zu einer solchen, wenn man sie nach sittlichen Gesetzen betrachtet, würde kein besonderes

\footnotetext{
${ }_{36}$ Talvez a passagem mais clara e conhecida onde ele próprio reconhece sua relação com a história da filosofia é seu comentário sobre Platão, onde ele afirma ser possível entender Platão melhor do que ele próprio se entendia (Cf. KrV, B 370).

37 A própria caracterização de uma disciplina como ciência já pressupõe a ideia de sistema. A exigência sistemática é ainda muito maior no âmbito prático, visto se tratar de um produto normativo da razão prática (Cf. KrV, B 86off.).

38 HRUSCHKA, 2004, 50, n. 16.
} 
Gesetz erfordert werden.]"39, é muito mais facilmente interpretada como simplesmente indicando que no grupo das ações indiferentes nem todas são absolutamente indiferentes. Mas essas que não são absolutamente indiferentes, não necessariamente são chamadas de "meramente indiferentes". Não há nada nessa passagem de Kant que estabeleça isso. ${ }^{40}$

d) A verdadeira questão que Hruschka não responde adequadamente é por que algumas ações indiferentes não precisam de uma lei permissiva da razão e outras sim. Em outras palavras, o que transforma uma ação que não é nem ordenada, nem proibida em objeto de uma lei? Ou ainda, a questão primeira é saber o que faz com que a razão tenha de conceder uma faculdade jurídica a certas ações e não a outras? A resposta de Hruschka é simplesmente que "do contrário, eu não teria liberdade de fazer ou deixar de fazê-las tal segundo minha vontade" (citação completa acima). Ora, esse dificilmente é um bom argumento, pois do contrário, eu não seria livre para decidir beber leite ou cerveja sem que eu estivesse assegurado por uma lei permissiva. Exatamente por não reconhecer a magnitude desse problema, que sua posição conduz naturalmente a pressuposição de que as leis permissivas funcionam como um ato jurídico perfeito e suficiente. Mas nesse caso, não há nenhuma consideração jurídica que distinga uma lei preceptiva de uma lei permissiva da razão. É exatamente isso, por sua vez, que faz com que sua interpretação da passagem do estado social para o estado civil seja tal que a função do estado seja simplesmente proteger e resguardar a propriedade que se estabeleceu unilateralmente no estado civil. Em suma, no final das contas, sua interpretação acaba transformando Kant em um liberal ao estilo de Locke e inclusive considerando

39 MS, AA 06:223.

40 Uma crítica muito semelhante é feita por Szymkowiak (2009, 576, n. 11). 
o estabelecimento da propriedade segundo um modelo estritamente unilateral, algo que Kant criticava abertamente ${ }^{41}$.

e) Finalmente, a tese central de Hruschka de que leis permissivas como "power confering norm" é tão correta, quanto irrelevante. O que quero dizer com isso é que todas as normas da razão já pressupõem implicitamente, de uma forma ou de outra, uma autorização para fazer uma ação. Uma lei preceptiva ao mesmo tempo que ordena já está autorizando. Da mesma forma que uma lei proibitiva já pressupõe a autorização para se usar de força contrária caso alguém não a cumpra. Até mesmo a liberdade, como único direito inato pode ser visto como uma norma que confere direitos, como direito à legítima defesa. Em suma, considerar que as leis permissivas envolvem uma autorização significa simplesmente reconhecer que elas implicam em si mesmas uma positividade com relação à possibilidade de impor ou proibir ações. Dito de outra forma, trata-se da própria positividade que está envolvida na noção de direito como um todo. Isso significa que o critério de ser "power confering norm" não serve como característica discriminatória da lei permissiva.

\section{Lei permissiva como um momento teleológico prático}

Nesta seção argumentarei que a lei permissiva da razão deve ser interpretada como comportando um momento teleológico prático no processo de derivação sistemática de deveres. A estratégia adotada é apresentar razões para se pensar uma teleologia prática na base do procedimento de derivação de deveres para com isso mostrar a legitimidade sistemática desse conceito. Em segundo lugar, mostra-se que a lei permissiva possui exatamente as características de uma teleologia prática nos

\footnotetext{
${ }^{41}$ Uma crítica parecida é desenvolvida por Flikschuh (2000) à interpretação liberal feita por Kersting (2007 - cito a terceira edição do livro de Kersting). Acredito que essa mesma crítica pode ser transposta aqui a Hruschka.
} 
seus fundamentos e, em seguida, indicam-se quais são as consequências dessa interpretação para a questão do direito de propriedade.

\subsection{Conceito de uma teleologia prática}

A teleologia é normalmente compreendida no sistema de Kant como tendo uma função exclusivamente teorética, isto é, como um momento intermediário e metodológico no processo de busca de conhecimentos acerca dos condicionados empíricos e leis empíricas, mais especificamente, aquelas vinculadas com questões das chamadas ciências da vida. Como mostrei em outros lugares, a teleologia em Kant não foi justificada e pensada para ser usada apenas nesse contexto teórico ${ }^{42}$. Ao contrário, ela é tanto um modelo para se pensar o próprio funcionamento sistemático da razão, na relação entre suas faculdades e usos (no sentido de uma meta-teoria transcendental), quanto para estabelecer uma ligação entre o âmbito da liberdade com a natureza. Nesse segundo contexto, a teleologia e o julgamento reflexionante teleológico se associam à liberdade e produzem uma teoria, cuja utilidade não é teórica, mas prática, surgindo assim a ideia de uma história universal com um propósito cosmopolita e a antropologia pragmática, por exemplo. Aqui, entretanto, pretendo levar a tese de uma teleologia prática mais adiante, ou seja, que ela não apenas está na base da criação de uma teoria de uso prático, no sentido da criação de um campo de sentido abrangente onde a razão prática pode contextualizar a realização dos deveres, mas também que a teleologia prática serve como um campo de sentido que contextualiza inclusive a própria determinação do que passa a ser considerado um direito e um dever. Talvez o caso mais claro desse segundo vínculo entre uma teleologia prática e a definição da existência de um dever seja o dever de promover o progresso da humanidade que se assenta não apenas na impossibilidade de provar sua invalidade, mas da possibilidade de sua realização, tal como

42 Cf. Klein $(2016 ; 2017 a)$. 
Kant apresenta na terceira seção do ensaio Sobre a expressão corrente: isso pode ser correto na teoria, mas de nada serve para a prática ${ }^{43}$.

É importante notar que aquilo que chamo aqui de teleologia prática não é a mesma estabelecida por uma razão prática estrito senso, isto é, não se trata aqui de fins que a razão prática pura estabelece como deveres, tal como ocorre no caso dos fins de virtude, ainda que ambas estejam estreitamente conectadas. Trata-se aqui de uma teleologia prática vinculada ao juízo reflexionante e que por isso possui as características básicas da teleologia, mas com aspectos práticos. Quais são essas características?

a) Ela se refere ao particular e contingente. A teleologia ou o princípio formal de conformidade a fins da natureza funciona como um guia do processo reflexivo quando não se está tratando das leis gerais da natureza, isto é, quando se precisa lidar com um particular dado ao qual não se possui um universal correspondente. Assim, o objeto da reflexão é essencialmente o contingente, aquele objeto que ainda não se determinou adequada e completamente segundo conceitos mecânicos da natureza.

b) Ela funciona como um procedimento metodológico e processual que não determina o objeto. O princípio de conformidade a fins da natureza é essencialmente um momento metodológico, mas necessário do operar da nossa razão (entendida no sentido amplo), quando se está lidando com o particular, mas também com a perspectiva de sistema. É um procedimento metodológico na medida em que não se está determinando o objeto a partir da conformidade a fins da natureza, mas se está construindo hipóteses para que se possa pensar sobre ele, ou seja, trata-se de uma forma de considerar o objeto cuja finalidade é servir como momento para que se possa gradativamente construir um conhecimento objetivo dele. Em suma, metodologicamente falando,

43 Cf. TP, AA 08: 310. 
a teleologia é um momento necessário, mas não suficiente de nossa investigação, pois por ele mesmo não se define o que o objeto é, mas sem ele, estar-se-ia fadado a "andar às apalpadelas" e sem um procedimento racional como guia de investigação.

c) Ela é pensada tendo em vista a perspectiva de ser substituída pelo julgamento determinante. Segundo Kant, de modo geral, todo o processo de investigação assume com princípio de investigação uma perspectiva teleologia, ou seja, considerada metodologicamente a teleologia nunca perderá sua função. Entretanto, as explicações, as quais assumem um modelo determinante das categorias do entendimento (no sentido da causalidade mecânica), gradualmente deverão substituir as reflexões teleológicas. Por determinante deve-se entender a utilização da categoria da causalidade para definir como de fato aquele objeto é possível.

d) A reflexão prática segue uma direção distinta daquela da reflexão teórica. Em geral, os elementos anteriores são características amplamente reconhecidas da reflexão teleológica em geral. É essa quarta característica que se apresenta como não devidamente reconhecida pela literatura secundária de Kant e para a qual chamo fortemente a atenção. A razão prática segue uma outra direção na estrutura da determinação do objeto, a saber, enquanto a razão no seu uso teórico parte do efeito para se chegar a causa, a razão no seu uso prático parte da causa para se gerar o efeito. Essa distinção, segundo Kant, é tão importante que deve ser levada em conta inclusive na determinação da estrutura da análise da faculdade. Assim a Crítica da razão prática segue uma ordem inversa àquela da Crítica da razão pura: essa parte de conceitos para se chegar a princípios, aquela parte de princípios para se chegar aos conceitos. Ora, da mesma forma que ocorre essa inversão do uso teórico da razão para seu uso prático, ocorre uma inversão similar quando se pensa a teleologia em seu uso teórico e quando se a pensa no seu uso prático. No âmbito da teleologia teórica o particular é dado e o princípio de conformidade a fins auxilia a busca pelo 
respectivo universal. No caso da teleologia prática, o universal é dado na ideia e o princípio de conformidade a fins deve servir como fio condutor para encontrar o particular, mais especificamente, leis particulares que permitirão com que aquele universal seja realizado na prática. Nesse caso, a teleologia prática, utilizando-se do princípio de conformidade a fins da natureza, estabelece um procedimento reflexivo que leva em consideração um conjunto de situações particulares e contingentes e indica quais delas seriam as mais adequadas para se promover a realização gradual do ideal normativo estabelecido deontologicamente pela razão (o aspecto deontológico indica aqui os princípios determinantes práticos da razão).

Se essa interpretação estiver correta, então boa parte da Metafísica dos Costumes, que trata exatamente da implementação dos princípios a priori do direito e da moral, pode ser considerada como seguindo um fio condutor a priori não puro. Em outras palavras, ainda se trata de um $a$ priori, pois parte de um princípio a priori, porém a sua aplicação deve ser feita sobre a natureza humana, a qual somente pode ser estabelecida e conhecida tendo em vista elementos empíricos. Essa transição, por sua vez, não é feita nem de modo arbitrário e contingente, nem de modo categórico dedutivo, ainda que alguns momentos da obra deem essa impressão. Na verdade, Kant se utiliza implicitamente de princípios reflexionantes teleológicos para essa transição entre os princípios universais a priori, isto é, aqueles que valeriam para todo e qualquer ser racional em geral, e aqueles princípios a priori não puros, que não são derivados estritamente da experiência, mas também precisam levar em conta elementos particulares da condição humana. Essa reflexão teleológica está implícita no processo de estabelecimento de deveres e deixa sua marca no próprio caráter da constituição de um sistema de deveres.

Por que Kant não apresenta ou fala explicitamente de uma reflexão teleológica no âmbito da sua doutrina do direito, por exemplo? Talvez porque sua intenção na Doutrina do direito era apresentar um sistema de 
direitos e deveres e não de considerações prudenciais e teleológicas que estão pressupostas no próprio processo de derivação de deveres. Dessa forma, o momento teleológico é simplesmente incorporado, mas também transformado pela normatividade prática que emana do imperativo categórico do direito. Por isso que não se está defendendo que existam deveres teleológicos na filosofia de Kant ou mesmo que esses deveres sejam justificados teleologicamente, mas que existam deveres que incorporam momentos teleológicos no seu estabelecimento. Na próxima seção pretende-se mostrar como isso ocorre no caso das leis permissivas, visto que elas acabam envolvendo em sua própria constituição essas características de uma teleologia prática.

\subsection{Fundamento teleológico da lei permissiva e suas implicações para o sistema de deveres}

Para mostrar que a lei permissiva carrega consigo elementos de um momento teleológico, utilizam-se os quatro aspectos apresentados acima como guias de análise.

a) Quanto ao objeto: A lei permissiva se vincula exatamente a um caso particular e a uma situação contingente. Em ZeF Kant afirma que os artigos preliminares 2, 3 e 4, "sem serem exceções à norma jurídica, tendo, porém, as circunstâncias da sua aplicação, ampliando subjetivamente a competência, contêm uma autorização para adiar a execução"44. Não é possível definir a priori, de uma maneira definitiva e absoluta, quais são essas circunstâncias que revogariam essa possibilidade de adiamento. Isso se aplica também ao caso do político moral que decide adiar a reforma da constituição tendo em vista o risco de destruição do próprio Estado. Com relação à aquisição da primeira propriedade, essa contingência da permissão se

${ }^{44}$ ZeF, AA 8: 347. 
expressa tanto da perspectiva da prioridade do primeiro proprietário, isto é, nada mais contingente do que ser o primeiro (pense-se no sentido de que apenas o primogênito pudesse ter direito à herança), quanto da perspectiva da amplitude do título. Se coloco uma bandeira no topo de uma montanha, sou dono do topo da montanha, de toda montanha ou até onde se estende minha visão? Kant sugere que minha propriedade se estenderia até onde eu consigo defendê-la, entretanto, também a força é um elemento racionalmente arbitrário que entra em consideração. A força é inclusive contingente em sua própria definição, pois depende de se estar pensando um indivíduo jovem, velho, um indivíduo ou grupo, ou ainda dependendo da época, até onde alcança uma lança, uma flecha, um tiro de canhão ${ }^{45}$ ou um míssil? Enfim, é fácil perceber a contingência e arbitrariedade que ela envolve.

b) Quanto ao seu aspecto procedimental: A lei permissiva envolve em si a ideia de um aspecto procedimental necessário, mas não suficiente para determinar o que é de direito. Poderíamos dizer, nesse sentido, que a lei permissiva envolve um aspecto positivo, ainda que sempre problemático. A lei permissiva envolve um momento necessário, pois sem ela nossa razão não conseguiria estabelecer uma transição entre o universal, a ideia de um sistema de liberdades, e o particular, que envolve a relação da liberdade do meu arbítrio empiricamente condicionado e sua atuação nesse mundo contingente tendo em vista a existência de outros arbítrios. Não é possível estabelecer a priori, segundo uma simples dedução, o quanto de propriedade eu posso ter, o quanto é muito e o quanto é pouco. Então, procedimentalmente, eu assumo, também a partir do princípio da honestidade jurídica, que um ato empiricamente contingente, como o de tomar posse

\footnotetext{
$45 \mathrm{Na}$ Doutrina do direito Kant menciona o tiro de canhão como um critério. Em outro lugar, Kant menciona o caso de Romulo quem estabeleceu sua vontade pela força, mas foi sucedido por Numa, quem criou o estado de direito. Ele observa que isso ocorreu de acordo com uma máxima implícita "para instituir um direito, a força precede o direito, de acordo com uma lei permissiva" (Metaphysik der Sitten Vigilantius, AA 27: 516, tradução nossa).
} 
e declarar que algo seja meu, como um ato legítimo, no sentido que isso coloca em andamento um processo no qual os indivíduos podem estabelecer novas relações, inclusive corrigindo e melhorando o que se aceita inicialmente. Nesse sentido, a lei permissiva permite aceitar o contingente, não por ele mesmo, mas como um momento em vista da ideia de direito. Trata-se da forma procedimental que a razão assume para lidar com o contingente. Por outro lado, a lei permissiva envolve sempre um aspecto problemático, pois o seu conteúdo não foi estabelecido de modo objetivo e determinado por ele mesma. Em outras palavras, ele não envolve um ato jurídico perfeito e acabado.

c) Quanto a sua relação com a determinação: o que a lei permissiva estabelece deve poder ser gradualmente substituído pelo direito peremptório. Note-se que entra aqui a perspectiva temporal de que aquilo que a lei permissiva estabeleceu de uma maneira problematicamente necessária, ou ainda, de uma maneira inevitável, mas ainda assim problemática, deve poder ser superado e melhorado ao longo do tempo. Assim, com o passar do tempo, os artigos preliminares 2, 3 e 4 de ZeF devem ser gradualmente implementados por completo, bem como a reforma das constituições não deve mais ser postergada. Da mesma forma ocorre com a propriedade privada, ela não mais deve ser estabelecida de modo unilateral ou bilateral, mas sim de modo onilateral, ou seja, segundo a perspectiva do conceito de vontade geral, do conceito de república e, finalmente, segundo a perspectiva cosmopolita. Numa verdadeira república, que funcionaria adequadamente segundo os princípios de liberdade, igualdade e independência, aquilo que o direito de propriedade estabelece de modo categórico e inequívoco em muito pouco seria assemelhado à situação produzida pelo direito de propriedade a partir da lei permissiva no estado social ou mesmo em um estado que precise de reformas e está distante da ideia de república. 
d) Quanto a sua normatividade regulativa prática: aqui entra o caráter propriamente prático regulativo implícito na lei permissiva. Nesse sentido, o primeiro aspecto digno de nota se refere à ideia de teleologia, isto é, a ideia de uma causalidade cujo conceito do efeito ou do fim já está implícito na causa. A lei permissiva não tem em vista apenas o que ela própria estabelece, mas ela é assumida em função de uma situação de direito futuro. Nesse sentido, a ideia dessa situação de direito futuro já está implícita na própria lei permissiva, a qual funciona como um momento de realização desse ideal jurídico normativo. ${ }^{46} \mathrm{O}$ segundo aspecto digno de nota se refere à relação com a qualidade dos juízos infinitos e sua relação com a lei permissiva. Os juízos de qualidade, quando esquematizados segundo o tópico da antecipação da percepção, são formulados no seguinte princípio: "em todos os fenômenos o real, que é um objeto da sensação, possui uma quantidade intensiva, isto é, um grau"47. Esse princípio tem como uma das consequências que não existe no fenômeno o nada absoluto, ou seja, a inexistência completa de sensação, mas que existe uma escala potencialmente infinita de realidade intensiva, a qual também nunca podermos estabelecer que seja a suprema. Mutatis mutandis, se fizéssemos uma analogia com a teleologia, poderíamos apontar da mesma forma que existe uma escala infinita de graus em que o direito precisa e pode ascender em relação a sua realização completa. Isso fica claro quando Kant fala da república noumenon como um ideal ${ }^{48}$ ou mesmo

\footnotetext{
46 Aqui vale a pena entrar em um pequeno debate com Flikschuh: $O$ fato dela não vincular o juízo reflexivo preliminar a uma perspectiva teleológica faz com que ela não perceba que, a partir de uma teleologia prática, o próprio conceito de fim já está pressuposto no ponto de partida. Em outras palavras, a ideia de cosmopolitismo em Kant já está implícita no ponto de partida, a saber, de uma posse originária comum do solo (MS: 06:266s), e de uma vontade unificada originariamente segundo a perspectiva onilateral. Ou seja, Flikschuh nega que a ideia de uma posse original da terra e de uma vontade geral estejam presentes já na lei permissiva (FLIKSCHUH, 2000, p. 147; 152). Entretanto, apesar dessa incongruência inicial, sua conclusão acerca da diferença entre Kant e Grotius, Flikschuh, (2000, p. 152) está de acordo com a interpretação aqui esboçada.

$47 \mathrm{KrV}, \mathrm{B} 207$.

${ }^{48}$ Cf. SF, AA 07: 91.
} 
que ninguém pode estabelecer um ponto final no qual não pudéssemos mais nos elevar no desenvolvimento da liberdade ${ }^{49}$.

A presente interpretação da lei permissa da razão teria as seguintes vantagens hermenêuticas e conceituais:

a) Em primeiro lugar, essa interpretação apresenta uma leitura sistemática que interpreta o conceito de lei permissiva segundo o espírito da obra kantiana. Ou seja, explica as lex permissivae não a partir da introdução de uma discussão terminológica estranha ao próprio sistema, mas segundo as categorias que foram moldadas por Kant durante ao menos as duas últimas décadas de vida.

b) Por um lado, permite compreender o ponto de partida do estabelecimento do direito como sendo algo que não contém em si uma cumplicidade com algo equivocado e corrompido (como acaba sugerindo a interpretação de Brandt e Flikschuh e que seria um erro sistemático gravíssimo de Kant, pois esse aspecto corrompido emanaria para todo o sistema), mas também, por outro lado, não atribui à lei permissiva o estatuto de um ato jurídico perfeito, o que tornaria praticamente incompreensível o papel que Kant atribui ao estado e à perspectiva cosmopolita (como é a consequência da leitura de Hruschka).

c) Permite entender a lei permissiva como um modus operandi de um direito fundado deontologicamente, mas projetado teleologicamente. Isso permite explicar e justificar uma série de supostas incongruências apontadas historicamente pelos leitores de Kant (como Tierney). Entre outras coisas, permite reconhecer a distinção com relação aos diferentes âmbitos do direito privado e público; na medida em que o direito possui uma capacidade adaptativa. Isso indica a processualidade implícita na própria filosofia do direito e política de Kant, o que tem implicações inclusive na forma como se deve ler a Doutrina do direito.

$49 \quad K r V B 374$. 
Nesse sentido, por exemplo, vincula-se de modo integrado à justificação da propriedade no nível do direito civil também o direito cosmopolita (não é possível justiça doméstica, sem justiça internacional), ou seja, a realização da vontade geral não está apenas no início, isto é, na justificação do estado, mas é também o objetivo do andamento do processo, a constituição de um direito cosmopolita. Da mesma forma, explica como a lei permissiva funciona como uma solução para a antinomia do direito, ou seja, de modo a considerar tanto a tese quanto a antítese como verdadeiras, e não apenas a posição defendida na tese ${ }^{50}$. Nesse sentido, minha leitura também responde às críticas de Tierney e Szymkowiak ${ }^{51}$.

\section{Consequências para a fundamentação do direito à propriedade}

Com relação a essa terceira seção, quero ressaltar que as teses aqui apresentadas se constituem mais como um ensaio sobre as peculiaridades de um conceito kantiano de propriedade do que como uma interpretação

\footnotetext{
5o Nesse sentido, segue-se aqui a interpretação de Flikschuh de que a lei permissiva da razão não é uma simples reafirmação sem restrições da perspectiva da tese da antinomia (FLIKSCHUH, 2000, p. 135).

51 Talvez uma leitura que tenha elementos parecidos a que estou defendendo seja a de Szymkowiak (2009), apesar de ele não fazer uma reconstrução sistemática interna ao sistema de Kant, mas tentar lançar luz a lógica da lei permissiva a partir da perspectiva histórica de Kant com Achenvall. Ele defende que a lei permissiva traz à tona um aspecto cético na filosofia política e jurídica de Kant, entendo por isso o estabelecimento de uma posse putativa que não pode ser entendida ainda como direito (SZYMKOWIAK, 2009, p. 591). Entretanto, por faltar a essa interpretação o arcabouço conceitual e sistemático da teleologia, segue-se que falta a sua leitura a capacidade de dar um horizonte de sentido e direcionamento para a proposta jurídica e política de Kant. Em outras palavras, falta a capacidade de unificar as diferentes partes da filosofia do direito e política de Kant no sentido de lhe conferir uma unidade sistemática. É como se Kant estivesse realizando concessões ad hoc para adequar o princípio do direito a uma realidade contingente. Nesse sentido, não consegue explicar a relação entre o direito privado, que é direito e não apenas uma posse putativa (como ele parece sugerir), e o direito cosmopolita. Assim ele assevera que há paradoxos e incertezas na perspectiva kantiana das relações internacionais "the most obvious example here is Kant's inconsistent advocacy for a world Federation of states" (SZYMKOWIAK, 2009, p. 598).
} 
textual da obra de Kant. A terceira seção é constituída dessa forma, ou seja, mais como um ensaio do que como uma interpretação não porque não acredito que seja possível sustentá-la textualmente e sistematicamente, mas porque a defesa minuciosa dessa posição, como sendo a posição de Kant, exigiria um artigo independente, visto que demandaria uma análise que obviamente ultrapassaria os níveis textuais superficiais, por conseguinte, tornaria esse artigo demasiado longo.

Assim, se essa leitura teleológica da lei permissiva e do direito de propriedade apresentada na seção anterior estiver correta, teríamos, entre outras, as seguintes consequências:

1. A propriedade não seria o fundamento do estado, como é o caso em Locke, isto é, a propriedade não possui um estatuto absoluto e o estado não surge para proteger os direitos dos proprietários, ao contrário, ele surge para estabelecer um modelo sistemático de contínuo aperfeiçoamento das relações de propriedade no sentido de que elas cada vez mais se coloquem de acordo com a ideia de vontade geral e de um sistema de propriedade adequado ao conceito de direito baseado no princípio de igual liberdade. Como a propriedade não surge como um ato jurídico perfeito, há um dever político e moral de aperfeiçoá-la segundo uma perspectiva teleológica a partir da ideia normativa de vontade geral e onilateral.

2. Como para Kant a propriedade se apresenta como um direito privado no estado pré-civil, segue-se que o Estado não pode, tal como permite o modelo Hobbesiano, simplesmente retirar a propriedade de alguém ou de algum grupo. A redistribuição pode ser justa, mas exigiria compensação. Essa compensação é o reconhecimento de que havia um direito anterior que não pode ser simplesmente desconsiderado pelo soberano. Já para Hobbes, como o soberano não precisa respeitar nenhum direito do estado de natureza, já que é ele propriamente a fonte do direito, ele também possui a legitimidade de modificar as 
relações de propriedade da forma como achar conveniente. Essa discricionariedade absoluta não é permitida pelo modelo kantiano. Além disso, a consideração de que há um direito de propriedade como um direito privado no estado social (estado de natureza) também faz com que se tenha instrumentos legítimos para questionar e criticar o procedimento mercantilista e imperialista das nações europeias ao lidarem com os povos das Américas, África e Ásia que ainda não haviam se organizado em estados. Em outras palavras, mesmo quando não existe uma relação jurídica entre povos (por meio da figura dos estados) ou mesmo quando ela se estabeleceu de modo precário, não há o direito de uso de força para retirar o que era possuído por outro, ou seja, o modelo político hobbesiano nas relações internacionais também se torna ilegítimo.

3. Poder-se-ia talvez comparar a perspectiva kantiana de uma teleologia no fundamento do conceito de propriedade com a cláusula da provisio de Locke no estado de natureza. Em outras palavras, poder-se-ia considerar equivalente a perspectiva de melhoramento das relações de propriedade no estado civil de Kant com a cláusula de Locke de que a legitimidade da primeira propriedade exigiria que se deixe aos outros a possibilidade de se apropriarem igualmente de uma mesma quantidade e qualidade de propriedade. Essa equivalência, entretanto, é equivocada, pois a provisio de Locke se refere estritamente à primeira aquisição, a qual por sua vez fica no momento inicial da instituição da propriedade e não opera mais depois da sua consolidação pelo Estado. Não há muito o que dizer quando a sociedade já está estabelecida e também não há como provar que a primeira aquisição não havia respeitado a cláusula do provisio. Entra aqui também a ambiguidade de se o estado de natureza em Locke é simplesmente uma ficção legitimatória ou é pensada como sendo um estado real no passado dos povos. Assumo aqui que se trata dos dois casos e é também por isso que a cláusula da provisio não possui qualquer efeito dentro da sociedade civil. Já a perspectiva 
de Kant, por outro lado, assume a inevitabilidade de que a primeira posse não será condizente com a ideia de um sistema onilateral de distribuição de propriedade, porém, isso é feito em benefício da própria criação de tal sistema. Isso faz com que o direito não seja concebido como algo que seja fundamentalmente negativo e corrompido, mas também não faz que ele seja visto tendo um início juridicamente perfeito. Por conseguinte, passa a ser não apenas legítimo, mas também um dever do soberano e uma exigência do próprio conceito de direito que ao longo da história se estabeleça um sistema contínuo de melhoramento de distribuição da propriedade. Em suma, a cláusula lockeana da provisio é política e juridicamente sem efeito no estado civil, enquanto a perspectiva kantiana estabelece uma exigência jurídica, política e moral do direito como um sistema de liberdades que se mantém continuamente presente para a avaliação do sistema do direito.

4. A perspectiva da justificação da propriedade em Kant assume, de certo modo, a perspectiva da vontade geral apresentada por Rousseau. Entretanto, apesar de Kant assumir parte do espírito da obra de Rousseau, ele também a modifica profundamente. Na medida que Rousseau não possui nenhuma teoria que lhe permita mediar sua perspectiva normativa com sua perspectiva descritiva, isto é, na medida em que ele recusa uma perspectiva teleológica mediadora ${ }^{52}$, resta-lhe apenas contar com a revolução e com o feliz acaso de que certas comunidades consigam encontrar as condições corretas para implementar o pacto social. Também por falta dessa perspectiva teleológica se estabelece uma ambiguidade com relação à propriedade em Rousseau, isto é, por um lado a propriedade inicia como que por um roubo ${ }^{53}$. Por outro lado, é exatamente

\footnotetext{
52 Sobre isso ver Klein (2017b).

53 Cabe lembrar sua famosa sentença de que a propriedade surgiu quando um indivíduo cerca ilegitimamente um pedaço de terra e encontra indivíduos suficientemente simples para lhe acreditar.
} 
a propriedade que cria condições para o desenvolvimento das relações de moralidade. De forma semelhante, o contrato social fala que o soberano tem o direito de dispor das vidas e da propriedade segundo a vontade geral, que busca igualdade de liberdade, mas essa vontade geral é ambígua porque ela fala que no estado civil cada um deve manter o que é seu. Em suma, fica em aberto a questão: o que é 'o seu' de cada um? Se formos para os seus textos políticos aplicados, como o Tratado sobre economia política, Projeto de constituição para a Córsega e as Considerações sobre o governo da Polônia vê-se que em nenhum momento Rousseau fala de desapropriação e divisão de propriedade, mas fala apenas do estabelecimento de impostos proporcionais à riqueza. Essas ambiguidades que não parecem poder ser adequadamente mediadas no contexto da filosofia de Rousseau, podem, entretanto, ser superadas com a inserção de uma perspectiva teleológica na justificação da propriedade e na perspectiva teleológica de seu contínuo aperfeiçoamento. Em primeiro lugar, para isso é preciso ver na própria aquisição da propriedade privada uma ação positiva e não imediatamente negativa. Em segundo lugar, esse aspecto positivo deve ser mantido, ainda que se estabeleça também uma exigência de aperfeiçoamento. Nesse sentido, a vontade geral e a ideia de contrato não são apenas conceitos normativos para a constituição e manutenção de uma sociedade justa (ou seja, para sociedades que foram felizes na sua constituição), mas são conceitos normativos e regulativos para o contínuo aperfeiçoamento de todas as sociedades, afinal nenhuma delas é a realização perfeita da república noumenon e também nenhuma nunca o será. De todo modo, ninguém pode estabelecer um ponto final no aperfeiçoamento, isto é, sempre é possível aperfeiçoar o sistema político e jurídico, pois não se pode colocar a priori um limite para o desenvolvimento da liberdade ${ }^{54}$.

54 Cf. KrV, B 374. 
5. A própria legitimação da propriedade no estado social, isto é, enquanto direito provisório já possui em seu cerne não apenas a legitimidade da realização da liberdade do proprietário, mas também e, sobretudo, a realização de um sistema de liberdades no estado civil. Aqui é importante notar que a ideia de uma vontade geral e a ideia da posse comum do solo são para Kant ideias a priori da razão prática e não conceitos historicamente construídos e, por isso mesmo, não são conceitos historicamente determinados. Isso significa que quando se fala de um sistema de direito tem-se em vista não apenas os direitos dos indivíduos de uma determinada comunidade historicamente situada e condicionada, mas a perspectiva diacrônica e cosmopolita da espécie humana. Disso podem se seguir profícuas perspectivas jurídicas e políticas. Talvez três delas já indiquem isso claramente: a) As relações de propriedade deverão ser pensadas também numa perspectiva sistêmica e cosmopolita. Assim, certos recursos naturais não pertencem apenas a um povo e não podem ser destinados exclusivamente para seu uso e benefício; b) A utilização da propriedade não é de absoluta discricionariedade do proprietário, isto é, ele não pode fazer um uso da propriedade que implique ou coloque em risco o uso dessa propriedade num sistema de direitos futuro, ou seja, há por exemplo, limites para a utilização de recursos naturais não renováveis por determinados povos ou mesmo por determinadas gerações. Mas quando o consumo de certo bem natural se torna inevitável, ele deve ser contrabalançado deixando-se para a próxima geração algo que ela não teria caso aquele consumo não houvesse sido realizado; c) Toda a produção de riqueza se deu com base em um sistema de propriedade em certa medida legítimo, mas também imperfeito. Essa imperfeição foi permitida tendo em vista a realização de um sistema de direito posterior que fosse cada vez mais justo. A partir disso, pode-se pensar na perspectiva de um conteúdo social de toda propriedade que limita seu uso. Assim, por exemplo, pode-se inclusive estipular limitações para propriedade privada ou o uso 
da propriedade intelectual. Dessa forma, por um lado, não se justifica simplesmente o direito como um status quo e, por outro, não se legitima o processo de aperfeiçoamento do sistema do direito segundo uma perspectiva utilitarista de promoção da felicidade. Em suma, é possível entender e explicar como o direito pode servir para moldar as condições históricas sem provocar rupturas e também sem se fundar em uma perspectiva utilitarista e paternalista, mas a qual possui, sobretudo, um potencial profundamente republicano e cosmopolita.

A partir dessas considerações é possível entrever o quanto essa interpretação do conceito de propriedade privada em Kant pode ser produtiva para se discutir questões políticas contemporâneas. Abre-se, com isso, um novo horizonte de trabalho para a filosofia kantiana e um novo modelo de discussão para a política, o qual trilha, por assim dizer, um caminho intermédio entre um liberalismo extremo, por um lado, e uma completa submissão à perspectiva estatal por outro. Da mesma forma, projeta-se uma discussão para além dos limites dos estados nacionais, inclusive para se pensar em problemas que serão cada vez mais frequentes, como os resultantes do aquecimento global e das grandes migrações.

\section{Referências}

BRANDT, Reinhard. Das Problem der Erlaubnisgesetze im Spätwerk Kants. In: HÖFFE, Otfried. (ed.). Immanuel Kant, Zum Ewigen Frieden. Berlin: Akademie Verlag GmbH, 2004. p. 69-72. https://doi.org/10.1524/9783050050270.69 FLIKSCHUH, Katrin. Kant and modern political philosophy. Cambridge: Cambridge University Press, 2000. https://doi.org/10.1017/CBO9780511487187 HRUSCHKA, Joachim. The permissive law of practical reason in Kant's Metaphysics of Morals. Law and Philosophy, Dordrecht, v. 23, n. 1, p. 45-72, jan. 2004.

KANT, Immanuel. A metafísica dos costumes. Tradução José Lamego. Lisboa: Calouste Gulbenkian, 2005. 
KANT, Immanuel. A paz perpétua e outros opúsculos. Tradução Artur Morão. Lisboa: Edições 70, 2004.

KANT, Immanuel. Crítica da faculdade do juízo. Tradução Valerio Rohden e António Marques. 2. ed. Rio de Janeiro: Forense Universitária, 2002.

KANT, Immanuel. Crítica da razão pura. Tradução Valerio Rohden e Udo Baldur Moosburger. São Paulo: Abril Cultural, 1980.

KANT, Immanuel. Fundamentação da metafísica dos costumes. Tradução, introdução e notas Guido Antônio de Almeida. São Paulo: Discurso Editorial, 2009. KANT, Immanuel. Gesammelte Schriften. Hrsg: Bd. 1-22 Preussische Akademie der Wissenschaften, Bd. 23 Deutsche Akademie der Wissenschaften zu Berlin, ab Bd. 24 Akademie der Wissenschaften zu Göttingen. Berlin: [s. n.], 1900.

KANT, Immanuel. Princípios metafísicos da doutrina do direito. Tradução e introdução Joãosinho Beckenkamp. São Paulo: Martins Fontes, 2014.

KAUFMANN, Matthias. Was erlaubt das Erlaubnisgesetz und wozu braucht es Kant? Jahrbuch für Recht und Ethik, [s. l.], v. 13, p. 195-219, 2005.

KERSTING, Wolfgang. Wohlgeordnete Freiheit: Immanuel Kants Rechts- und Staatsphilosophie. 3. erweiterte und durchgesehene Auflage. Paderborn: Mentis, 2007.

KLEINGELD, Pauline. Kant and cosmopolitanism: the philosophical ideal of world citizenship. Cambridge: Cambridge University Press, 2012. https://doi. org/10.1017/CBO9781139015486

KLEIN, Joel Thiago. A questão da teleologia: Kant leitor de Rousseau. Cadernos de Filosofia Alemã, São Paulo, v. 22, n. 1, p. 51-70, 2017b. https:// doi.org/10.11606/issn.2318-9800.v22i1p51-70

KLEIN, Joel Thiago. The practical-regulative teleology and the idea of a universal history in the Critique of pure reason. In: SANTOS, Leonel Ribeiro; LOUDEN, Robert B.; MARQUES, Ubirajara R. de Azevedo. (org.). Kant e o a Priori. São Paulo: Cultura Acadêmica, 2017a. v. 1, p. 291-302.

KLEIN, Joel Thiago. Reflexão teleológica e o caráter da espécie humana na antropologia de um ponto de vista pragmático. Peri, Florianópolis, v. 8, n. 1, p. 12-44, 2016.

LOCKE, John. Dois tratados do governo civil. São Paulo: Martins Fontes, 2005. 
LORIAUX, Sylvie. Grotius and Kant on original community of goods and property. Grotiana, [s. l.], v. 38, n. 1, p. 106-128, 2017. https://doi.org/10.1163/1876075903800007

ROUSSEAU, Jean-Jacques. Considerações sobre o governo da Polônia e sua projetada reforma. In: ROUSSEAU, Jean-Jacques. Rousseau e as relações internacionais. Tradução Sérgio Bath. São Paulo: Imprensa Oficial, 2003.

ROUSSEAU, Jean-Jacques. Emílio ou Da educação. Tradução Roberto Leal Ferreira. 4. ed. São Paulo: Martins Fontes, 2014.

ROUSSEAU, Jean-Jacques. O contrato social. Tradução Antonio de Pádua Danesi. São Paulo: Martins Fontes, 1999.

ROUSSEAU, Jean-Jacques. Projeto de constituição para a Córsega. In: ROUSSEAU, Jean-Jacques. Rousseau e as relações internacionais. Tradução Sérgio Bath. São Paulo: Imprensa Oficial do Estado, 2003.

ROUSSEAU, Jean-Jacques. Tratado sobre a economia política. In: ROUSSEAU, Jean-Jacques. Rousseau e as relações internacionais. Tradução Sérgio Bath. São Paulo: Imprensa Oficial, 2003.

SZYMKOWIAK, Aaron. Kant's permissive law: critical rights, sceptical politics. British Journal for the History of Philosophy, Bristol, v. 17, n. 3, p. 567-600, 2009. https://doi.org/10.1080/09608780902986656

TIERNEY, Brian. Kant on property: the problem of the permissive law. Journal of the History of Ideas, Baltimore, v. 62, n. 2, p. 301-312, Apr. 2001. https:// doi.org/10.1353/jhi.2001.0020

TIERNEY, Brian. Permissive natural law and property: Gratian to Kant. Journal of the History of Ideas, Baltimore, v. 62, n. 3, p. 381-399, July 2001. https:// doi.org/10.1353/jhi.2001.0031

WEINRIB, Jacob. Permissive laws and the dynamism of Kantian justice. Law and Philosophy, Dordrecht, v. 33, n. 1, p. 105-136, Jan. 2014. https://doi. org/10.1007/s10982-013-9175-4

YPI, Lea. A permissive theory of territorial rights. European Journal of Philosophy, Oxford, v. 22, n. 2, p. 288-312, June 2012. https://doi.org/10.1111/ j.1468-0378.2011.00506.x 